DOI http://dx.doi.org/10.1590/1678-49442016v22n2p595 GIORGI, Gabriel. 2014. Formas comunes: animalidad, cultura, biopolítica. Buenos Aires: Eterna Cadencia. 302 pp.

\section{Felipe Magaldi}

Programa de Pós-Graduação em Antropologia Social do Museu Nacional, Universidade Federal do Rio de Janeiro/RJ, Brasil

Gabriel Giorgi faz parte de uma instigante nova geração de intelectuais latino-americanos destinada a pensar a contrapelo o pós-estruturalismo. O investigador argentino é mestre em Sociosemiótica pela Universidad Nacional de Córdoba e doutor em Spanish and Portuguese pela New York University, onde atualmente se desempenha como professor. Sua obra tem transitado, desde a última década, entre os campos da literatura, do gênero e da filosofia através de variadas publicações, tais como Sueños de extermínio: homosexualidad y representación en la literatura argentina (2004), da qual é autor, e Excesos de vida: ensayos sobre biopolítica (2007), em que foi co-editor.

Formas comunes: animalidad, cultura e biopolítica (também publicado em português pela editora Rocco, em 2016, sob o título Formas Comuns: animalidade, literatura, biopolítica), seu livro mais recente, se insere em uma extensa fortuna crítica que, desde os anos 1970, tem reabilitado os potenciais do conceito foucaultiano de biopolítica para o estudo das relações entre corpo, vida e poder. Sua aposta reside na articulação entre algumas das principais questões desse campo de pesquisa - notadamente as que tratam do surgimento de práticas divisórias que, em virtude de raça, classe, gênero e sexualidade, estabelecem hierarquias entre corpos e formas de vida - e a temática da animalidade, que emerge no zeitgeist de falência do humanismo e de denúncia da separação entre natureza e cultura delineada no pensamento ocidental moderno.

O território privilegiado em que o autor se propõe a tecer seu fio de reflexão é a produção cultural latinoamericana (especialmente literatura, mas também cinema e artes visuais) a partir dos anos 1960. Giorgi se embasa na observação de que se a vida animal se constituiu historicamente como o "outro absoluto" do humano, aproximando-se apenas de seu filão "selvagem", a mesma passa a ressurgir nos repertórios estéticos letrados da América Latina com uma nova roupagem. Anuncia-se, dessa vez, através de uma espécie de contiguidade - orgânica, afetiva, material e política - à vida humana, enovelando-se à temática do corpo e de seus desejos, doenças, paixões e afetos.

Assim, a partir da análise de materiais produzidos por artistas 
heterogêneos, o autor se dedica a questionar em que medida a evocação da figura do animal é capaz de produzir deslocamentos nas matrizes de distinção entre vidas inteligíveis como "humanas" e "animais", e mais amplamente, entre vidas a "proteger" ou "futurizar" e vidas a "esquecer" ou "abandonar". A partir dessa trama, evidencia-se um jogo de distribuições em que o que conta como "pessoa" ou como "não-pessoa" (sensu Roberto Esposito) é a todo tempo instável e contingente, sendo passível de inversões, e mobilizando corpos de distintas - ou não tão distintas naturezas.

Formas Comunes é dividido em cinco partes, permeadas de sete capítulos. Na introdução, Giorgi já anuncia suas hipóteses fundamentais, afirmando que o efeito das produções que deslocam a figura do animal do marco de uma natureza intangível é o de iluminar as políticas que inscrevem e classificam corpos sobre ordenamentos hierárquicos, assim como as economias da vida e da morte que produzem esses corpos, atribuindo para eles lugares e sentidos em um mapa social. Desta forma, o autor desnuda linhas de interseção entre cultura e biopolítica, redefinidoras dos próprios limites destas searas, nas quais a imaginação do animal (mais que sua "representação") opera como um artefato de contestação da ontologia humanista e de seus marcos de inteligibilidade.
A primeira parte da obra, intitulada "La Rebelión Animal", inclui uma imersão no conto "Meu Tio o Iauaretê" (1950), do escritor brasileiro Guimarães Rosa (cap. 1). O texto trata do encontro entre um narrador sertanejo, mestiço e pobre e um interlocutor proveniente do mundo urbano e letrado. Giorgi descreve o primeiro personagem, empregado por fazendeiros locais para exterminar onças, como uma figura sem lugar na ordem estabelecida, abrigando linhas de indeterminação a partir das quais se abrem modos possíveis de resistência e de devir-animal (no sentido deleuzoguattariano). O pesquisador não lê na interação entre o narrador e seu interlocutor a produção de síntese, mas de ininteligibilidade recíproca. Entretanto, reconhece sua potência na capacidade de desterritorializar a um só tempo a ordem modernocapitalista e a indígena, assim como a distinção entre humanos e não humanos, sugerindo a possibilidade de "um comum não humanista" que permite pensar a biopolítica como cosmopolítica (sensu Viveiros de Castro).

A segunda parte da obra, chamada "Una Nueva Proximidad: Las Casas, Los Mataderos, El Pueblo", conta com três capítulos. Seu primeiro segmento (cap. 2) se detém principalmente sobre outro texto brasileiro, o romance A Paixão segundo G. $H$ (1964), de Clarice Lispector. 
Trata-se agora do ambiente doméstico de um apartamento carioca, no qual a vida de uma mulher burguesa e de sua empregada Janair é afetada pela irrupção de uma barata. Giorgi descreve a aproximação narrativa que se estabelece entre o inseto e a empregada no continuum biopolítico dos corpos. Entretanto, esta não é sustentada em termos antropogênicos, isto é, a partir de uma humanitas que se estende a outros entes, mas sim no registro inverso de um vivente que excede os limites do humano. Concomitantemente, a fisiologia da barata é debulhada até se abrir a uma interioridade abismal, um "plasma" onde Giorgi encontra uma concepção de vida como pura zona de passagem, questionando os próprios limites do corpo como princípio de individuação, em referência a Simondon.

O segmento subsequente (cap. 3) parte de uma temática particular - qual seja, a da importância dos matadouros para a cultura popular argentina do século XX - e a partir de então se move por textos distintos, com destaque para El matadero (2009), de Martín Kohan, que trata do abismo ético despertado em um motorista de caminhão ao descobrir um carregamento de animais a caminho do abatedouro; e Bajo este sol tremendo (2009), de Carlos Busqued, que consiste em um relato sobre violência e sequestros entre Córdoba e o Chaco cuja narrativa é saturada de animais mortos. Giorgi encontra nessas produções, que chama de "ma- tadouros da cultura", o fracasso da função política de separar a morte da vida e o animal do humano através de uma rígida demarcação. Assim, lê nesses textos o questionamento das operações que, sob o signo do capital, envolvem corpos de animais e de trabalhadores em relações de exploração econômica, tornando-os mercadoria.

O terceiro segmento da segunda parte (cap. 4) segue no campo literário argentino, tratando sobretudo de Osvaldo Lamborghini e seu primeiro texto, "El Fjord" (1969). Trata-se de um conto que, no contexto do movimento peronista nos anos 1960, é habitado por criaturas "degeneradas", figuras contra natura engajadas em orgias, assassinatos e canibalismo, aproximando o povo da animalidade. Giorgi sustenta que a potência desse conteúdo narrativo, criador de um mundo de paixões insaciáveis, é inscrever corpos que escapam à representação no universo do Estado. Dita inscrição, no entanto, revela-se ao fim e ao cabo impossível e incontrolável. Evidencia-se assim uma reinscrição da ordem biopolítica sob o signo de sua falha, a um só tempo mantendo e borrando as fronteiras concebidas por Agamben entre bios e zoé.

"Series", a terceira parte, toma em seu primeiro segmento (cap. 5) a relação entre morte e imaginação política na América Latina. Para tanto, refere-se a obras como o romance 2666 (2004), do chileno Robert Bo- 
laño, que trata do desaparecimento de cadáveres de mulheres em uma cidade fictícia inspirada em Ciudad Juárez; o documentário Nostalgía de la Luz (2010), do também chileno Patricio Guzmán, ambientado no deserto do Atacama, que cruza observatórios astronômicos e resquícios mortais de indígenas, mineiros e desaparecidos políticos; e instalações diversas da artista mexicana Teresa Margolles, que incluem restos de cenas de crimes ligados à guerra contra as drogas em seu país de origem. Em comum, nesses trabalhos reside a materialidade dos restos corporais como terreno de contestação dos regimes que os marcam. Articula-se, assim, a biopolítica à tanatopolítica, entendida como seu reverso sistemático e complementar, na qual se produz, em escala massiva, corpos sem pessoa e pessoas sem corpo.

O segundo segmento dessa parte (cap. 6) opera no cruzamento entre corpos, sexualidades, desejos não normativos e animalidade. Primeiramente, Giorgi recorre ao livro El Beso de La Mujer Araña, do argentino Manuel Puig (1976), que narra o relacionamento de um preso político com seu companheiro de cela homossexual, perpassado pela figura da mulher-animal presente no filme Cat People (1942), de Jacques Tourneur. Na sequência, transita por textos diversos da obra de João Gilberto Noll, cujos personagens são descritos como "figuras acéfalas", de uma existência marcada por memó- ria e identidade difusas, tensionando o próprio estatuto do humano como sujeito de enunciação. Finalmente, cita Misales, da escritora uruguaia Marosa di Giorgio, que constrói, em cenas rurais, a descoberta da sexualidade de mulheres atravessada pelo testemunho de animais. Giorgi não enxerga nessas interseções um somatório de diferenças, mas a reinvenção do comum entre os corpos.

A quarta parte, "La Rebelión Animal (2)", evoca La Ciudad de Las Ratas (1979), do escritor argentino Copi (cap. 7), que tematiza uma rebelião contra humanos protagonizada por ratos parisienses. A tensão entre os mundos de cada uma dessas espécies, longe de apresentar-se como excludente, afigura-se antes como um tráfico permanente, constituindo uma zona irredutível ao ordenamento e à lei. Nesse contexto, sustenta Giorgi, a distinção entre cidadão e não cidadão conta mais que aquela entre humano e animal.

"Coda", a quinta e última parte da obra, condensa os efeitos produzidos pela incursão nos conteúdos trabalhados ao longo do livro. O autor aponta para a diluição da coincidência entre indivíduo e corpo individuado - implicando que não há corpo que não seja multiplicidade, seja ele demarcado como humano ou não humano - e para a relação entre vida e propriedade - instilando que todo corpo se faz visível sob o cálculo do capital - como suas principais sugestões. 
Com Formas comunes, Giorgi produz um curioso cruzamento entre animalidade, cultura e biopolítica no qual estes próprios conceitos são incessantemente deslocados, em homologia aos próprios fenômenos que se propõem a descrever. Seu corpus empírico, mais do que meramente ilustrativo, é tomado em seu caráter produtivo. Distanciando-se de leituras que buscam produzir sínteses niveladoras, e ao mesmo tempo sem descartar categorias supostamente essencialistas, como cultura e América Latina, o autor encontra um caminho no qual é possível conhecer sem dispersar nem reduzir. Trata-se, portanto, de um exercício contagiante, acessível mesmo para leitores que desconheçam previamente seu material analítico, transitando com maestria entre a filosofia, as artes e as ciências humanas.

DOI http://dx.doi.org/10.1590/1678-49442016v22n2p599 “Coleção Aulas Inaugurais". 2016. Projeto Nova Cartografia Social. Edição Alfredo Wagner Berno de Almeida. Organização: Patrícia Maria Portela Nunes, Maria Consolação Lucinda, Cynthia Carvalho Martins, Camila do Valle e Alfredo Wagner Berno de Almeida. Rio de Janeiro/ São Luís: Casa 8.

\section{Rita de Cássia Melo Santos}

Professora adjunta da Universidade Federal da Paraíba, João Pessoa/PB, Brasil
Formulada no âmbito do Programa de Pós-Graduação em Cartografia Social e Política da Amazônia da Universidade Estadual do Maranhão (PPGCSPA-Uema), a "Coleção Aulas Inaugurais" constitui uma iniciativa pedagógica inovadora no âmbito do ensino da pós-graduação no país. Ao conjugar as aulas inaugurais propriamente ditas com o memorial dos seus autores, a coleção amplia suas possibilidades de leitura e permite aos estudantes uma dupla aproximação com a pesquisa e a trajetória institucional e pessoal de pesquisadores estabelecidos. A leitura das aulas possibilita a introdução aos temas das ciências sociais, a releitura de trabalhos consagrados e a interposição de novas questões a pesquisas concluídas, enquanto o memorial proporciona uma leitura transversal do campo científico por meio de suas redes de relações políticas, sociais e afetivas estabelecidas ao longo do tempo. A interlocução entre a aula inaugural e o memorial constitui a possibilidade da leitura crítica da produção acadêmica, das circunstâncias sociopolíticas e do campo científico por meio do qual esses autores constituíram seus trabalhos e instituições.

Fundado em 2013, o PPGCSPA-Uema foi um desdobramento das ações de pesquisa e ensino realizadas pelo Projeto Nova Cartografia Social da Amazônia (PNCSA) e pelo Grupo de Estudos Socioeconômicos da Amazônia (Gesea). Voltada para 